\title{
Balloon dilatation of the pulmonary valve in the first year of life in patients with tetralogy of Fallot: a preliminary study
}

\author{
S A QURESHI, C R KIRK, * R K LAMB, † R ARNOLD, J L WILKINSON \\ From the Department of Paediatric Cardiology, Royal Liverpool Children's Hospital, Liverpool
}

SUMMARY Fifteen infants with tetralogy of Fallot, who would otherwise have required a palliative operation, underwent balloon dilatation of the right ventricular outflow tract. The mean period palliation was 8.5 months (range 0-26 months). The procedure was performed without seriouss complications on $88 \%$ of occasions.

This preliminary study suggests that balloon dilatation may be useful in the management $\overrightarrow{8 f}$ tetralogy of Fallot.

Some centres believe that the optimum time for correction of tetralogy of Fallot is after two years of age. The need for a palliative operation before this is determined by the severity of cyanosis and the frequency of cyanotic spells, both of which are related to the degree of right ventricular outflow tract obstruction. Palliative operation, however, has an appreciable mortality. The systemic to pulmonary artery shunts may require revision because of shunt failure and this may increase the risks of the subsequent definitive operation.

Balloon dilatation is an established treatment for pulmonary valve stenosis. We have used this technique in the management of an unselected group of infants with tetralogy of Fallot who would otherwise have required a palliative operation.

\section{Patients and methods}

Between December 1983 and December 1986, 15 infants (nine boys and six girls) had 24 balloon dilatations of the pulmonary valve for tetralogy of Fallot. Five children required more than one balloon procedure-two children had two, two children had three, and one child had four balloon dilatations on separate occasions. Their mean age at the first procedure was 3.3 months (range $0.5-9$ months).

Requests for reprints to Dr S A Qureshi, Department of Paediatric Cardiology, Guy's Hospital, St Thomas Street, London SE1 9RT.

Present addresses: ^Harefield Hospital, Harefield; †Southampton General Hospital, Southampton.

Accepted for publication 18 May 1988
Tetralogy of Fallot was an isolated finding in nire children. Two children had an associated persistent arterial duct, two had a secundum atrial septal defec $\xi_{\circ}^{\circ}$ one an atrioventricular septal defect, and one had an aorto-pulmonary collateral artery as the sole bloog supply to the left pulmonary artery.

On 19 occasions balloon dilatation of the pulmon? ary valve was performed because the patients we becoming increasingly cyanosed and on five occasions it was performed because of frequent cyanotic spells. In our hospital, all patients with tetralogy of Fallot who were being considered for palliative treatment underwent balloon dilatation as the procedure of choice rather than a shunt. Early the series, the pulmonary valve could not be crossed at cardiac catheterisation in five patients. Treatmera

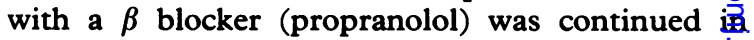
patients already on this treatment but was not starteg. for the first time at the time of balloon dilatation.

Cardiac catheterisation and angiocardiographg were carried out under general anaesthesia in ap cases. The mean systemic arterial oxygen saturatiog was $75 \%$ (range $46-97 \%$ ) and the mean pulmonary artery oxygen saturation was $64 \%$ (range $46-80 \%$. The mean right ventricular outflow tract gradient measured on 15 occasions, was $70 \mathrm{~mm} \mathrm{Hg}$ (range $56 \mathrm{w}$ $83 \mathrm{~mm} \mathrm{Hg}$ ).

We used balloons with external diameters of $15 \mathrm{~mm}$ for dilatation. The size of the balloon ws selected on the basis of the size of the pulmonate valve annulus measured from the lateral projection of the right ventricular angiogram. Early in the serieg. dilatation was performed with balloons that we latef recognised were too small. In the later cases we used 
balloons with diameters that were approximately 33$40 \%$ larger than the pulmonary annulus. An exchange guide wire was passed through a 5 French Cournand or Multipurpose catheter and the tip was positioned in the distal right pulmonary artery. The balloon catheter was advanced over the guide wire until the midpoint of the balloon lay at the valve annulus. The balloon was inflated with dilute contrast to a pressure of 3-4 atmospheres and deflated immediately. For each dilatation procedure the balloon was inflated between two and four times. When we used larger balloons a constriction persisted at the site of the pulmonary valve annulus. The femoral artery pressure was monitored with a cannula whenever possible. The systemic and pulmonary oxygen saturations and right ventricular outflow tract gradient were measured at the end of the procedure.

\section{Results}

\section{HAEMODYNAMIC FUNCTION}

On 20 occasions the systemic arterial oxygen saturation increased by a mean of $18 \%$ (range $6-38 \%$ ), on two occasions it remained the same, and on two occasions it deteriorated by $4 \%$ and $17 \%$. Overall the systemic arterial oxygen saturation improved to a mean of $87 \%$ (range $65-98 \%$; $<<0.05$ ) after dilatation. The mean oxygen saturation in the pulmonary artery was $68 \%$ (range $52-89 \%$ )) after dilatation and did not differ significantly from the value before dilatation. The mean residual systolic gradient across the right ventricular outflow tract was $64 \mathrm{~mm} \mathrm{Hg}$ (range 45-83 $\mathrm{mmHg}$ ). The gradient was increased in two patients by $10 \mathrm{~mm} \mathrm{Hg}$; however, the systemic artery saturation improved by $37 \%$ in one and by $12 \%$ in the other.

\section{COMPLICATIONS}

In all children there was a transient period of hypotension and bradycardia during balloon inflation, with spontaneous recovery within 30 seconds.

Table 1 Patients adequately palliated by balloon dilatation

\begin{tabular}{lrrrrrrr}
\hline & \multicolumn{1}{c}{ Case No } & & & & \\
\cline { 2 - 8 } & 1 & 2 & 3 & 4 & 5 & 6 & 7 \\
\hline $\begin{array}{c}\text { Age at presentation } \\
\text { (mnth) }\end{array}$ & 1.8 & 9 & 0.3 & $0 \cdot 1$ & $0 \cdot 3$ & 0.3 & $0 \cdot 1$ \\
$\begin{array}{c}\text { Age at first dilatation } \\
\text { (mnth) }\end{array}$ & 2 & 9 & 0.5 & 0.5 & 9 & 10 & 3 \\
$\begin{array}{c}\text { Age at follow-up } \\
\text { (mnth) }\end{array}$ & 20 & 18 & $4 \star$ & $4 \cdot 5$ & 35 & 27 & 7 \\
$\begin{array}{c}\text { Period of } \\
\text { palliation (mnth) }\end{array}$ & 18 & 9 & 3.5 & 4 & 26 & 26 & 4 \\
\hline
\end{tabular}

^Died.
Table 2 Patients who required systemic-pulmonary artery shunt after dilatation

\begin{tabular}{lllll}
\hline & \multicolumn{3}{l}{ Case No } \\
\cline { 2 - 5 } & 8 & 9 & 10 & 11 \\
\hline Age at presentation (mnth) & $1 \cdot 8$ & 5 & 2 & 0.6 \\
Age at first dilatation (mnth) & 3 & 6 & $2 \cdot 5$ & 1 \\
Age at shunt (mnth) & 3 & 9 & 3 & 3 \\
Period of palliation (mnth) & 0 & 3 & 0.5 & 2 \\
\hline
\end{tabular}

Two children required a short period of intermittent positive pressure ventilation after the procedureone because of increasing cyanosis two hours after dilatation ( 11 days later a Waterston shunt was inserted) and the other because transient pulmonary oedema developed 18 hours after dilatation. In one patient group D streptococcal septicaemia developed after the procedure. This was treated with appropriate antibiotics. He died suddenly at home three months later, having been symptom free for three weeks; at necropsy vegetations were found on the tricuspid valve.

\section{OUTCOME}

Six children have not required further intervention during a mean follow up of 12.9 months (range 3.526 months). Four children have had a systemic to pulmonary artery shunt a mean of 1.6 months (range 0-3 months) after dilatation and four children have had a corrective operation six to 10 months (mean 8 months) after dilatation (tables 1-3).

\section{OPERATIVE FINDINGS}

The pulmonary artery and valve were inspected at the time of surgical correction. In two patients the valve was tricuspid without any evidence of tears affecting the cusps or commissures. The other two valves had tears; in one the valve was tricuspid and there was a split along the commissure between the posterior and the left cusps and in the second patient there was a tear of the posterior cusp itself. We saw no tears in the pulmonary arteries.

Table 3 Patients who had surgical correction after balloon dilatation of the pulmonary valve

\begin{tabular}{lrrrrr}
\hline \multicolumn{5}{l}{ Case No } \\
\cline { 2 - 5 } & 12 & 13 & 14 & 15 \\
\hline Age at presentation (mnth) & 1 & 3 & 7 & $0 \cdot 3$ \\
Age at first dilatation (mnth) & 3 & 3 & 7 & 2 \\
Age at correction (mnth) & 13 & 12 & 13 & 9 \\
Period of palliation (mnth) & 10 & 9 & 6 & 7 \\
\hline
\end{tabular}




\section{Discussion}

The mortality for total correction of tetralogy of Fallot is between $1 \%$ and $5 \% .^{1}$ Although operation during infancy is associated with only a small increase in the frequency of early deaths, young age and small size remain important risk factors. ${ }^{1}$ Many centres therefore recommend a staged approach with the creation of a systemic to pulmonary artery shunt before complete correction. ${ }^{2-4}$ This has the advantage of reducing the intensity of cyanosis and the frequency of cyanotic attacks. It also promotes the growth of the pulmonary valve annulus and the pulmonary arteries, which may reduce the need for insertion of transannular patches at the corrective operation and thus reduces the operative risks and achieves a better functional outcome..$^{5-7}$

The creation of systemic to pulmonary artery shunts is, however, not without risk. The operative mortality of Blalock-Taussig and Waterston shunts varies between $0 \%$ and $13 \%{ }^{18-12}$ Approximately $10 \%$ of Blalock-Taussig shunts became occluded ${ }^{11}$ and up to $16 \%$ of Waterston shunts produce kinking of the pulmonary arteries or pulmonary hypertension or both. ${ }^{12-14}$ Shunt failure may require either total correction before the optimum time or the formation of a second shunt; both procedures increase the risks of total correction. ${ }^{1}$ In view of these problems there may be a place for an alternative form of palliation.

Balloon dilatation is now a recognised method of treatment for pulmonary valve stenosis and has recently been applied to pulmonary artery stenosis and hypoplasia..$^{1516} \mathrm{We}$ have extended its use to infants with tetralogy of Fallot as an alternative form of palliation to systemic to pulmonary artery shunt operations. In this study adequate non-surgical palliation was achieved in $11(73 \%)$ infants and four of them later had elective total correction. Dilatation is simple to perform and can be repeated if necessary. It requires an inpatient stay of only 48 hours compared with a stay of about seven days for a systemic to pulmonary artery shunt and does not need the resources of a cardiothoracic surgical centre. It also does not seem to increase the risks of subsequent corrective surgery.

Balloon dilatation for pulmonary valve stenosis, however, is not without risk. The potential immediate complications include the production of arrhythmias, haemorrhage, and femoral vein thrombosis. ${ }^{17}$ There are also reports of damage to the right ventricular outflow tract $^{18}$ and the pulmonary valve, ${ }^{15}$ trunk, ${ }^{19}$ and branch arteries. ${ }^{16}$ Twenty one $(88 \%$ ) of our procedures were uncomplicated and of the four children who have undergone correction the only notable findings were splitting of the commissures. Previous balloon dilatation did not cause any intraoperative complications.

We could not predict the subgroup of children who did not benefit from balloon dilatation. We are als uncertain of the effect of this procedure on the growth of the pulmonary annulus and artery. Patients with a predominantly valvar component the right ventricular outflow tract obstruction mi benefit most from this procedure.

This preliminary study suggests that balloôn dilatation may be useful in the management of infan $\overrightarrow{t s}$ with severe tetralogy of Fallot and that it should be considered for the initial palliative treatment.

\section{References}

1 Kirklin JW, Barratt-Boyes BG. Cardiac surgery. Nêw York: Wiley Medical, 1986:767-78.

2 Stephenson LW, Friedman S, Edmunds LH Jr. Sta surgical management of tetralogy of Fallot in infans. Circulation 1978;58:837-41.

3 Kirklin JW, Blackstone EH, Pacifico AD, Brown R $\overrightarrow{0}$, Bargeron LM Jr. Routine primary repair vs two sta 8 repair of tetralogy of Fallot. Circulation 1979;60:37 86.

4 Rittenhouse EA, Mansfield PB, Hall DG, et Tetralogy of Fallot: selective staged management.J Thorac Cardiovasc Surg 1985;89:772-9.

5 Gale AW, Arciniegas E, Green EW, Blackstone EPP, Kirklin JW. Growth of the pulmonary anulus and pulmonary arteries after the Blalock-Taussig shunt $J$ Thorac Cardiovasc Surg 1979;77:459-65.

6 Kirklin JW, Bargeron LM Jr, Pacifico AD. The eी largement of small pulmonary arteries by preliminofy palliative operations. Circulation 1977;56:612-7.

7 Alfieri O, Blackstone EH, Parenzan L. Growth of the pulmonary anulus and pulmonary arteries after the Waterston anastomosis. $J$ Thorac Cardiovasc Sung 1979;78:440-4.

8 Arciniegas E, Farooki ZQ, Hakimi M, Perry BL, Greein EW. Classical shunting operations for congeni cyanotic heart defects. J Thorac Cardiovasc Sighg 1982;84:88-96.

9 Guyton RA, Owens JE, Waumett JD, Dooley KG, Hatcher CR Jr, Williams WH. The Blalock-Taussig shunt: low risk, effective palliation, and pulmonazy artery growth. J Thorac Cardiovasc Surg 1983;85: 917-22.

10 Parenzan L, Alfieri O, Vanini V, et al. Waterston anastomosis for initial palliation of tetralogy of Fallog. $J$ Thorac Cardiovasc Surg 1981;82:176-81.

11 Kay PH, Capuani A, Franks R, Lincoln C. ExperienRe with the modified Blalock-Taussig operation usif polytetrafluoroethylene (Impra) grafts. Br Heart $\mathrm{WJ}^{J}$ 1983;49:359-63.

12 Gay WA, Ebert PA. Aorta to right pulmonary artery anastomosis causing obstruction of the right pulmofary artery: management during correction of tetralogy of Fallot. Ann Thorac Surg 1973;16:402-10.

13 Newfeld EA, Waldmann JD, Paul MH, et al. Pulmo ary vascular disease after systemic-pulmonary arter 81 shunt operations. Am J Cardiol 1977;39:715-20. 
14 Tay DJ, Engle MA, Ehlers KH, Levin AR. Early results and late developments of the Waterston anastomosis. Circulation 1974;50:220-9.

15 Lock JE, Keane JF, Fellows KE. Interventional cardiac catheterisation. In: Macartney FJ, ed. Congenital heart disease. Lancaster: MTP Press, 1986:169-71.

16 Lock JE, Castaneda-Zuniga WR, Fuhrmann BP, Bass JL. Balloon dilatation angioplasty of hypoplastic and stenotic pulmonary arteries. Circulation 1983;67: 962-7.

17 Kveselis DA, Rocchini AP, Snider R, Rosenthal A,
Crowley DC, Dick M II. Results of balloon valvuloplasty in the treatment of congenital valvar pulmonary stenosis in children. Am J Cardiol 1985;56: 527-32.

18 Ring JC, Kulik TJ, Burke BA, Lock JE. Morphological changes induced by dilatation of the pulmonary valve annulus with overlarge balloons in normal newborn lambs. Am J Cardiol 1985;55:210-4.

19 Lamb RK, Qureshi SA, Arnold R. Pulmonary artery tear following balloon valvoplasty in Fallot's tetralogy. Int J Cardiol 1987;15:347-9. 